\title{
Polyandry in Lepidoptera: a heritable trait in Spodoptera exigua Hübner
}

\author{
LUIS M. TORRES-VILA*†, M. CARMEN RODRÍGUEZ-MOLINA†, \\ JUAN GRAGERA $\ddagger$ \& PABLO BIELZA-LINO§ \\ $\uparrow$ Departamento de Fitopatología, Servicio de Investigación y Desarrollo Tecnológico (SIA), Finca La Orden, \\ Apdo. 22, E-06080 Badajoz, Spain, $₫$ Departamento de Hortofruticultura, Servicio de Investigación \\ y Desarrollo Tecnológico (SIA), Finca La Orden, Apdo. 22, E-06080 Badajoz, Spain and §Departamento de Ingeniería \\ Aplicada, ETS Ingenieros Agrónomos, Universidad Politécnica de Cartagena, Paseo de Alfonso XIII, 34, E-30203 \\ Cartagena, Murcia, Spain
}

\begin{abstract}
The genetic basis as well as the mode of inheritance of polyandry in Spodoptera exigua Hübner was studied in the laboratory by using a simple divergent selection experiment followed by $F_{1}$ reciprocal crosses, $\mathrm{F}_{2}$ and backcrosses. There was an effective response to artificial selection for high ( $\mathrm{H}$ line $)$ and low (L line) female mating frequency with significant separation of the lines by the second generation of selection. The mean female mating frequency in the parental generation (1.57 matings per female) reached plateaus of 2.50 and 1.25 matings per female in the $\mathrm{H}$ and $\mathrm{L}$ lines, respectively, after six generations of selection. Selection response becomes saturated at about $90 \%$ and $25 \%$ levels of polyandry (percentage females re-mating) in the $\mathrm{H}$ and $\mathrm{L}$ lines, respectively, and consequently monoand polyandric pure strains were not obtained. Polyandry levels in offspring from the $\mathrm{H}$ and $\mathrm{L}$ lines and their hybrids in $F_{1}, F_{2}$ and backcrosses consistently indicate that female mating frequency was more or less proportional to the relative amounts of genes derived from the $\mathrm{H}$ and $\mathrm{L}$ lines. Such a clear pattern of hybrid responses, together with the gradual selective changes under artificial selection, suggests the involvement of a polygenic system. Female mating frequencies from progeny of the two reciprocal $F_{1}$ crosses were not significantly different, which suggest that the trait was autosomally inherited. Moreover, female mating frequency of $F_{1}$ (pooled) progeny was not significantly different from the mid-parental value, which suggest no dominance. The computation of the Cavalli's joint scaling test consistently confirmed these results yielding values of $d=0.51 \pm 0.10$ and $h=0.12 \pm 0.21$. The broad sense heritability estimate was $H^{2}=0.73$. It is concluded that polyandry in S. exigua is a polygenic, autosomal heritable trait and that additive genetic variance is available for selection for female mating frequency. The implications of the genetic basis of polyandry are briefly discussed in the context of current theories about this crucial insect mating system.
\end{abstract}

Keywords: heritability, inheritance, mating frequency, multiple mating, polyandry, polygenic control, Spodoptera exigua.

\section{Introduction}

Insect species are usually classified as monandrous or polyandrous if most females exhibit single or multiple mating, respectively. Polyandry is a crucial female behaviour because this inevitably results in sperm competition and may be accompanied by cryptic female choice. Knowledge of factors regulating polyandry is important in the study of the evolution and adaptive significance of insect mating systems. Issues include evolutionary ecology, sexual behaviour, conflict of

*Correspondence. E-mail: 1torresv@aym.juntaex.es interests between sexes, mating benefits and costs, parental investment and female (offspring number and fitness) or male (paternity) reproductive output and success (see Choe \& Crespi, 1997; Birkhead \& Moller, 1998; for recent extensive reviews).

The occurrence of polyandry in insects has been shown to be determined by an array of environmental and morpho-physiological factors. From these, major, widely recognized factors regulating polyandry in Lepidoptera include male quality, size of the spermatophore received by females, female size, adult feeding, shortdistance interactions between sexes, sex ratio and/or population density (see for example Torres-Vila et al., 1997; McNeil et al., 1997 and references therein). 
A genetic basis regulating polyandry was suggested in early studies of female mating frequency (Burns, 1968; Pliske, 1973), and is assumed in both evolutionary theory (e.g. Halliday \& Arnold, 1987; Arnold \& Halliday, 1988; Sherman \& Westneat, 1988; Cheng \& Siegel, 1990) and mathematical models (Curtsinger, 1991; Zonneveld, 1992, 1996; Haig \& Bergstrom, 1995; Yasui, 1997). However, despite the importance of polyandry in the evolution of insect mating systems, virtually no data on the genetic basis and the mode of inheritance of this trait have been reported in non-social insects (but see Solymar \& Cade, 1990; on Gryllus integer). In Lepidoptera, the genetic basis of polyandry has not yet been experimentally determined.

The aim of this paper was to assess the genetic background and investigate the mode of inheritance of polyandry in the beet army worm, Spodoptera exigua Hübner, chosen as polyandrous lepidopteran model species.

\section{Materials and methods}

\section{General procedures, stock cultures and rearing}

A laboratory culture of $S$. exigua was established with 50 adults collected from light traps at La Orden, Guadajira, Badajoz, Extremadura, south-western Spain $\left(6^{\circ} 40^{\prime} \mathrm{W}, 38^{\circ} 51^{\prime} \mathrm{N}, 198 \mathrm{~m}\right.$ asl; UTM coordinates: 29SQD 024030) in September 1998. Moths were placed in 7-L cylindrical paper cages for mating and oviposition, and fed on a sugar solution ( $10 \%$ sucrose and $0.5 \%$ ascorbic acid) at $25 \pm 1{ }^{\circ} \mathrm{C}, 60 \pm 10 \%$ r.h. under a LD 16:8 photoperiod (about 2000 lux photophase light intensity). Eggs laid were surface-sterilized to prevent the spread of viral diseases by exposure to a formaldehyde atmosphere for about $4 \mathrm{~h}$. After hatching, larvae were mass reared in $150 \mathrm{~cm}^{3}$ cylindrical clear plastic containers at a density of 30-50 larvae per container. When larvae reached the third instar, they were transferred to individual 9-cm Petri dishes to avoid cannibalism and held until pupation. Larvae were provided with excess semisynthetic diet (slightly modified from Poitout \& Bues, 1970).

\section{Selection test for polyandry}

The offspring from field-collected adults was used as parental stock. Single pairs (a 1-day-old virgin female and a 2-3 day-old virgin male) were caged in $0.5 \mathrm{~L}$ cellophane bags and provided ad libitum sugar solution. Males were replaced every 4-5 days (or daily if damaged or dead) by another 2-3 day-old virgin male until the female died. The egg complement of each female was kept in a single $150 \mathrm{~cm}^{3}$ container and the offspring reared as indicated above. To assess polyandry, all females were dissected after death and the number of spermatophores in the bursa copulatrix recorded.

Two divergent lines were selected from the parental generation for high ( $\mathrm{H}$ line) or low ( $\mathrm{L}$ line) female mating frequency, i.e. for polyandrous or monandrous phenotypes, for six generations. The number of females tested per generation per line was usually $20-50$, but the number of fertilized females obtained was somewhat lower (10-30, unusually less than 10 ) because the mating success of $S$. exigua single pairs was often poor in the laboratory. Moreover, the number of females tested in the last generations of selection (4th to 6th) in the L line was also reduced, because mating success drastically declined, presumably because of high inbreeding and susceptibility to viral diseases.

The mating frequency of all females was determined in each generation and the offspring from females mated $\geqslant 2$ times ( $\mathrm{H}$ line) or once (L line) were selected to make up the next generation. We usually selected offspring from 8 to 12 females in each line or from all available females if fewer individuals were available. In the L line, once-mated females were randomly selected while in the $\mathrm{H}$ line 4- and 3-times mated females were selected first. Because it was not known if genes influencing polyandry (a sex-limited trait) were present in the male, in each generation females were mated with their male siblings. Unmated (having no spermatophores) and mated but unfertilized females were excluded from the data analysis.

\section{Crossing experiments}

The $\mathrm{F}_{1}$ reciprocal crosses between $\mathrm{L}$ and $\mathrm{H}$ lines were made in the 4th generation of selection. This was followed by $F_{2}$ crosses and all possible backcrosses. Single pairs were caged in $0.5 \mathrm{~L}$ cellophane bags as usual. The mating frequency of the female offspring of these crosses was determined as described above.

\section{Data analysis}

Data were tested for normality and the appropriate nonparametric or parametric tests were performed. The Mann-Whitney $U$-test was employed for all pairwise comparisons of means between the two selected lines throughout generations of selection, because of occasional deviations from normality in female mating frequency and female longevity distributions, due particularly to both the semiquantitative nature of the analysed variables and occasional small sample sizes. The $t$-test was used to detect differences in mean female mating frequency between $F_{1}$ offspring and the midparental value from both parental lines. For correlations, 
linear regression analysis was used (Scherrer, 1984; Sokal \& Rohlf, 1995).

Additive $(d)$ and dominance $(h)$ components in the inheritance of polyandry were estimated employing the Cavalli's joint scaling test (model of means). The parameters $\mathrm{A}, \mathrm{B}$, and $\mathrm{C}$ were previously calculated to test the adequacy of the additive-dominance model using Mather's formulae (Mather \& Jinks, 1982).

\section{Results}

Female mean mating frequency in the parental generation (1.57, range $1-4, n=42$, Fig. 1a) was quite similar to the value obtained from field-derived mated females caught in light traps in the same area $(1.48$, range $1-5$, $n=547$; L.M. Torres-Vila and J.N. McNeil, unpublished). Although it is widely known that field collections may underestimate the lifetime polyandry within a natural population, our results indicate that female mating frequency in the laboratory was not in disagreement with the estimation of polyandry in field conditions.

Artificial selection for high (H line) or low (L line) female mating frequency resulted in significant separation of the lines by the second generation (Fig. 1a), which clearly indicates that polyandry has a genetic basis. The $\mathrm{H}$ line had already attained a mean female mating frequency as high as 2.42 by the second generation of selection compared with 1.57 in the parental generation. It increased again to 2.64 in the third generation after which there was a plateau reached at 2.50. In the contrary, in the L line, mean mating frequency diminished from 1.57 to about 1.30 , remaining stable at this low level (Fig. 1a). A similar response was obtained when polyandry was estimated as the percentage of polyandrous females (percentage females re-mating) in each generation of selection (Fig. 1b). Thus, changes in polyandry include both an increase in mean mating number among re-mated females and in the percentage of females that re-mated.

Despite the significant response to selection for female mating frequency, we obtained neither $100 \%$ nor $0 \%$ polyandrous females in the $\mathrm{H}$ or $\mathrm{L}$ lines after six generations of selection, and consequently poly- or monandric pure strains were not obtained (Fig. 1b).

It is interesting to note that female mean longevity (10-16 days), a biotic variable potentially genetically correlated with polyandry, was not significantly affected by any of the selections ( $\mathrm{L}$ and $\mathrm{H}$ lines) throughout the selection experiment (Mann-Whitney $U$-test, G1: $U=199.0$; $\mathrm{G} 2: U=77.5$; $\mathrm{G} 3: U=24.5$; $\mathrm{G} 4: U=1.5$; $\mathrm{G} 5$ : $U=6.5$; G6: $U=5.0$; in all six pairwise comparisons $P>0.25$ NS, d.f. $=1)$. This excludes that selection for polyandry may have actually (inadvertently) operated
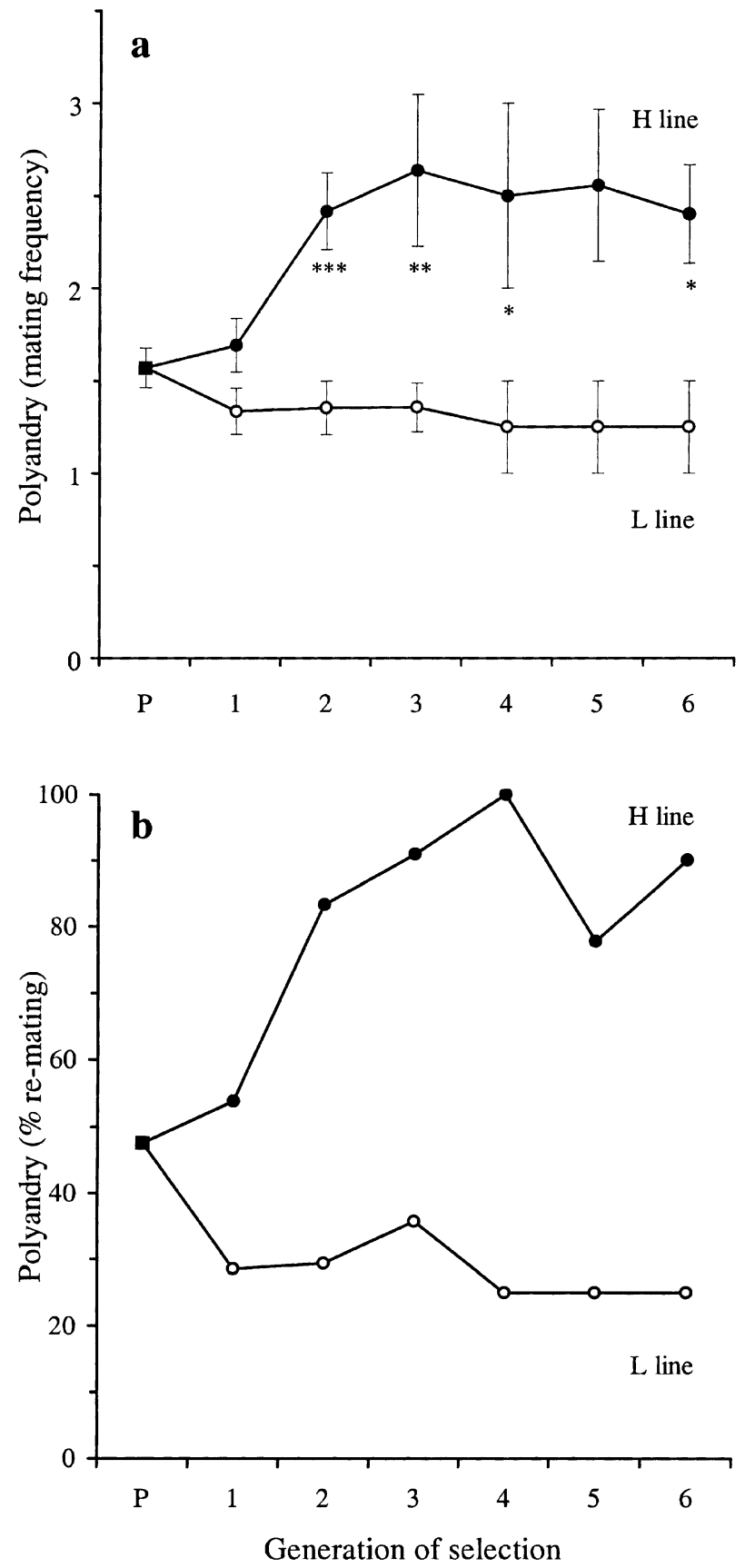

Fig. 1 Incidence of polyandry in two lines of Spodoptera exigua selected for low (L line) and high ( $\mathrm{H}$ line) female mating frequency. (a) Polyandry estimated as female mating frequency (i.e. mean number of spermatophores per female). Means in the $\mathrm{H}$ line shown with one, two or three asterisks are significantly different from the corresponding means in the L line at the $P<0.05, P<0.01$ and $P<0.001$ levels, respectively (Mann-Whitney $U$-test), G1: $U=199.0, P=0.072$ NS; G2: $U=77.5, P=0.0 ; \mathrm{G} 3: U=24.5, P=0.002$; G4: $U=1.5, P=0.040 ; \mathrm{G} 5: U=6.5, P=0.060 \mathrm{NS}$; G6: $U=5.0$, $P=0.025$; $($ d.f. $=1)$. Vertical bars are standard errors.

(b) Polyandry estimated as the percentage of females re-mating. 
on female longevity and not on polyandry itself. A similar situation occurred with female body size, another variable also potentially affecting polyandry. Although female size was not measured in our study, differences in this variable between the two selections were not evident.

The response to divergent selection appeared to be asymmetrical at first sight (Fig. 1a,b) with an apparently greater response to selection in the $\mathrm{H}$ line than in the $\mathrm{L}$ line. However, some degree of caution is needed since the number of matings per mated female in the L line has obviously an absolute minimum of one.

The results from $F_{1}$ and $F_{2}$ crosses and backcrosses indicate that polyandry in the hybrid offspring was more or less proportional to the relative amounts of genes derived from the $\mathrm{H}$ and $\mathrm{L}$ lines. Therefore, between the $\mathrm{H} \times \mathrm{H}$ and the $\mathrm{L} \times \mathrm{L}$ crosses there was a graded decrease in polyandry, estimated as both female mating frequency (Fig. 2a) and percentage of females re-mating (Fig. 2b). Moreover, a significant regression was obtained from these crosses between the mating frequency of daughters $(y)$ on mothers (x) $\quad(y=0.481 x+0.913 ; n=14 ; \quad r=0.80 ; \quad F=20.86$; $P=0.001)$.

The broad sense heritability estimate for female mating frequency was $H^{2}=0.73$ by using the expression (Sánchez-Monge \& Jouvé, 1984):

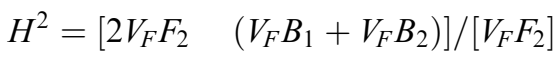

with $V_{F} \mathrm{~F}_{2}, \quad V_{F} \mathrm{~B}_{1}$ and $V_{F} \mathrm{~B}_{2}$ being the phenotypic variances in $F_{2}$ (pooled), $B_{1}$ (pooled backcrosses between $F_{1}$ and $H$ line) and $B_{2}$ (pooled backcrosses between $F_{1}$ and $L$ line), respectively (see Fig. 2).
Female mating frequencies from progeny of the two reciprocal $\mathrm{F}_{1}$ crosses $(\mathrm{H} \times \mathrm{L}$ and $\mathrm{L} \times \mathrm{H}$; Fig. 2a) were not significantly different $(2.06 \pm 1.21$ vs. $1.92 \pm 0.93$ matings per female, respectively; Mann-Whitney $U$-test, $U=218.5, P=0.95 \mathrm{NS})$. These results strongly suggest that polyandry is autosomally inherited, i.e. there is no evidence for a greater than proportional maternal sexlinked contribution. Thus, despite polyandry being a female-limited trait, genes coding for the trait are also carried by males. This fact may explain the lack of significant response to selection in the first generation of selection (Fig. 1a), because females in the parental generation were mated to males chosen at random, i.e. no information was available about the genes carried by male parents (estimated in their female siblings).

Female mating frequency of both $\mathrm{F}_{1}$ progenies was intermediate to those of the parental lines (Fig. 2a). Moreover, female mating frequency of $F_{1}$ (pooled) progeny $(1.98 \pm 1.05$ matings per female, $n=42)$ was not significantly different from the mid-parental value (1.91 matings per female, 5th generation) ( $t$-test, twotailed, $t=0.502$, d.f. $=41, P=0.62$, NS), indicating that (most) genes regulating polyandry in $S$. exigua are not dominant, but rather additive.

These results were consistent with the results from the Cavalli's joint scaling test (Table 1). Mather's parameters $\mathrm{A}, \mathrm{B}$ and $\mathrm{C}$ were not significantly different from zero in all seven cases, so the additive-dominance model was adequate for the analysis of the variation in polyandry. Lack of differences between models I and II and between models III and IV permitted the computation of models $\mathrm{V}$ and VI, respectively. In the same manner, lack of differences between models $\mathrm{V}$ and VI permitted the computation of the global model VII

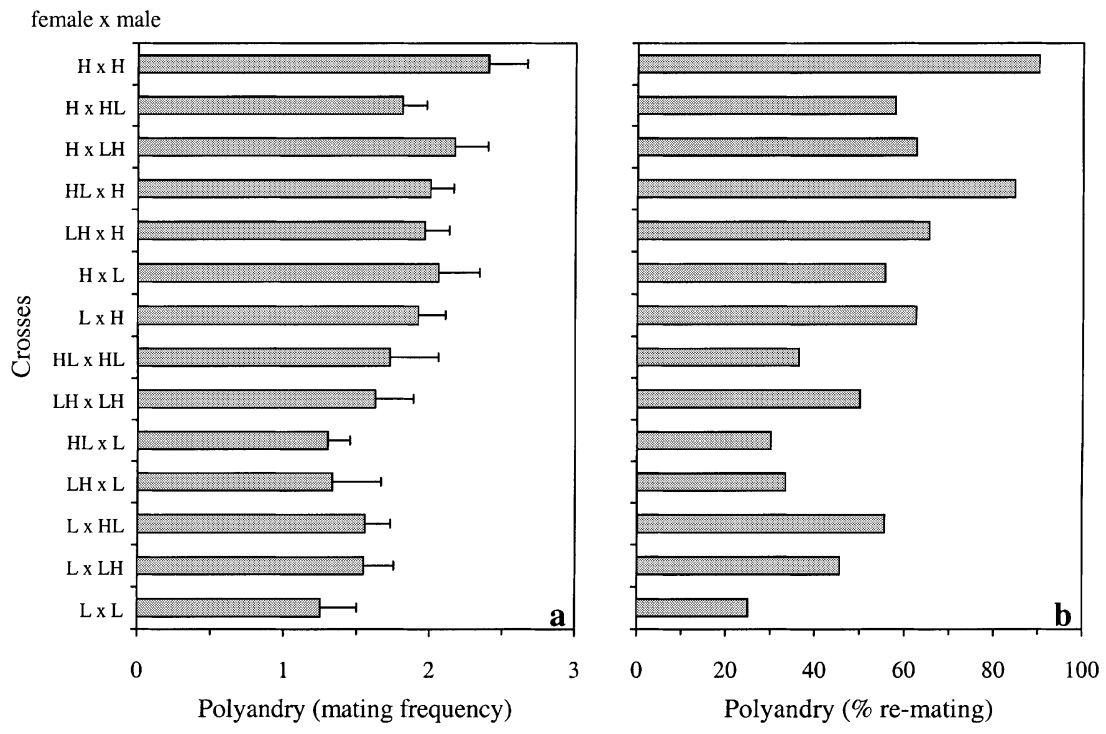

Fig. 2 Incidence of polyandry in $\mathrm{F}_{1}$ and $\mathrm{F}_{2}$ crosses and backcrosses between two lines of Spodoptera exigua selected for low (L line) and high ( $\mathrm{H}$ line) female mating frequency. (a) Polyandry estimated as female mating frequency (i.e. mean number of spermatophores per female). Horizontal bars are standard errors. (b) Polyandry estimated as the percentage of females re-mating. See text for statistical analysis.

(C) The Genetics Society of Great Britain, Heredity, 86, 177-183. 
Table 1 The results of the Cavalli's joint scaling test for polyandry in Spodoptera exigua

\begin{tabular}{lccccccc}
\hline & I & II & III & Model IV & V & VI \\
\hline A & $-0.84 \pm 0.51$ & $-0.46 \pm 0.51$ & $0.02 \pm 0.57$ & $-0.39 \pm 0.47$ & $-0.71 \pm 0.46$ & $-0.20 \pm 0.43$ & $-0.42 \pm 0.37$ \\
B & $-0.19 \pm 0.52$ & $-0.71 \pm 0.49$ & $-0.08 \pm 0.52$ & $-0.50 \pm 0.74$ & $-0.46 \pm 0.45$ & $-0.17 \pm 0.47$ & $-0.32 \pm 0.36$ \\
$\mathrm{C}$ & $-0.85 \pm 1.49$ & $-0.85 \pm 1.49$ & $-0.98 \pm 1.18$ & $-0.98 \pm 1.18$ & $0.85 \pm 1.49$ & $-0.98 \pm 1.18$ & $-0.87 \pm 1.00$ \\
$m$ & $1.71 \pm 0.13$ & $1.77 \pm 0.13$ & $1.80 \pm 0.13$ & $1.75 \pm 0.13$ & $1.71 \pm 0.12$ & $1.77 \pm 0.12$ & $1.70 \pm 0.11$ \\
$d$ & $0.45 \pm 0.12$ & $0.58 \pm 0.12$ & $0.57 \pm 0.13$ & $0.52 \pm 0.13$ & $0.49 \pm 0.11$ & $0.54 \pm 0.12$ & $0.51 \pm 0.10$ \\
$h$ & $0.10 \pm 0.28$ & $-0.05 \pm 0.27$ & $0.07 \pm 0.23$ & $0.05 \pm 0.24$ & $-0.01 \pm 0.26$ & $0.06 \pm 0.23$ & $0.12 \pm 0.21$ \\
$\chi^{2}$ & 2.71 & 2.71 & 0.77 & 1.45 & 2.68 & 0.82 & 2.19 \\
d.f. & 3 & 3 & 3 & 3 & 3 & $0.44 \mathrm{NS}$ & $0.84 \mathrm{NS}$ \\
$P$ & $0.44 \mathrm{NS}$ & $0.44 \mathrm{NS}$ & $0.86 \mathrm{NS}$ & $0.69 \mathrm{NS}$ & $0.53 \mathrm{NS}$ \\
\hline
\end{tabular}

Values \pm standard errors. A, B and C are the Mather's parameters to test the adequacy of the additive-dominance model, and $m$, $d$ and $h$ the mean, dominance and additive components, respectively (Mather \& Jinks, 1982).

Models were constructed as follows:

Model I: $\mathrm{P}_{1}=\mathrm{H} \times \mathrm{H}, \mathrm{P}_{2}=\mathrm{L} \times \mathrm{L}, \mathrm{F}_{1}=\mathrm{H} \times \mathrm{L}, \mathrm{F}_{2}=\mathrm{HL} \times \mathrm{HL}, \mathrm{B}_{1}=\mathrm{H} \times \mathrm{HL}, \mathrm{B}_{2}=\mathrm{L} \times \mathrm{HL}$.

Model II: $\mathrm{P}_{1}=\mathrm{H} \times \mathrm{H}, \mathrm{P}_{2}=\mathrm{L} \times \mathrm{L}, \mathrm{F}_{1}=\mathrm{H} \times \mathrm{L}, \mathrm{F}_{2}=\mathrm{HL} \times \mathrm{HL}, \mathrm{B}_{1}=\mathrm{HL} \times \mathrm{H}, \mathrm{B}_{2}=\mathrm{HL} \times \mathrm{L}$.

Model III: $\mathrm{P}_{1}=\mathrm{H} \times \mathrm{H}, \mathrm{P}_{2}=\mathrm{L} \times \mathrm{L}, \mathrm{F}_{1}=\mathrm{L} \times \mathrm{H}, \mathrm{F}_{2}=\mathrm{LH} \times \mathrm{LH}, \mathrm{B}_{1}=\mathrm{H} \times \mathrm{LH}, \mathrm{B}_{2}=\mathrm{L} \times \mathrm{LH}$.

Model IV: $\mathrm{P}_{1}=\mathrm{H} \times \mathrm{H}, \mathrm{P}_{2}=\mathrm{L} \times \mathrm{L}, \mathrm{F}_{1}=\mathrm{L} \times \mathrm{H}, \mathrm{F}_{2}=\mathrm{LH} \times \mathrm{LH}, \mathrm{B}_{1}=\mathrm{LH} \times \mathrm{H}, \mathrm{B}_{2}=\mathrm{LH} \times \mathrm{L}$.

Model V: $\mathrm{P}_{1}=\mathrm{H} \times \mathrm{H}, \mathrm{P}_{2}=\mathrm{L} \times \mathrm{L}, \mathrm{F}_{1}=\mathrm{H} \times \mathrm{L}, \mathrm{F}_{2}=\mathrm{HL} \times \mathrm{HL}, \mathrm{B}_{1}=\mathrm{H} \times \mathrm{HL}+\mathrm{HL} \times \mathrm{H}, \mathrm{B}_{2}=\mathrm{L} \times \mathrm{HL}+\mathrm{HL} \times \mathrm{L}$.

Model VI: $\mathrm{P}_{1}=\mathrm{H} \times \mathrm{H}, \mathrm{P}_{2}=\mathrm{L} \times \mathrm{L}, \mathrm{F}_{1}=\mathrm{L} \times \mathrm{H}, \mathrm{F}_{2}=\mathrm{LH} \times \mathrm{LH}, \mathrm{B}_{1}=\mathrm{H} \times \mathrm{LH}+\mathrm{LH} \times \mathrm{H}, \mathrm{B}_{2}=\mathrm{L} \times \mathrm{LH}+\mathrm{LH} \times \mathrm{L}$.

Model VII: $\mathrm{P}_{1}=\mathrm{H} \times \mathrm{H}, \mathrm{P}_{2}=\mathrm{L} \times \mathrm{L}, \mathrm{F}_{1}=\mathrm{H} \times \mathrm{L}+\mathrm{L} \times \mathrm{H}, \mathrm{F}_{2}=\mathrm{HL} \times \mathrm{HL}+\mathrm{LH} \times \mathrm{LH}$,

$\mathrm{B}_{1}=\mathrm{H} \times \mathrm{HL}+\mathrm{HL} \times \mathrm{H}+\mathrm{H} \times \mathrm{LH}+\mathrm{LH} \times \mathrm{H}, \mathrm{B}_{2}=\mathrm{L} \times \mathrm{HL}+\mathrm{HL} \times \mathrm{L}+\mathrm{H} \times \mathrm{LH}+\mathrm{LH} \times \mathrm{H}$.

that yields the more accurate estimates of $m, d$ and $h$ (Table 1), which clearly indicates both the existence of a strong additive component $(d=0.51 \pm 0.10)$ and the lack of a significant dominance effect $(h=0.12 \pm 0.21)$. In conclusion, the results strongly suggest the involvement of a polygenic system regulating polyandry in S. exigua.

\section{Discussion}

A number of explanations have been proposed for the adaptive advantages of polyandry, including additional sperm supply (to counteract infertile first matings, avoid female-male genetic incompatibilities, achieve potential fecundity and/or ensure fertility), acquisition of maletransferred nutrients and increased genetic variability of offspring. Concurrently, several potential costs of re-mating may balance these benefits such as increased exposure to male-borne parasites and diseases, energy and time wastage or increased risks of male-derived physical injury and predation (Walker, 1980; Thornhill \& Alcock, 1983; Drummond, 1984; Ridley, 1988; Hunter et al., 1993; Choe \& Crespi, 1997; McNeil et al., 1997; Birkhead \& Moller, 1998; Yasui, 1998). Alternatively, Halliday \& Arnold (1987) proposed that polyandry in some species may merely be a by-product of the selection on males to maximize polygyny, and thus offer no benefits for females. This hypothesis is controversial and its general applicability contested because its adaptive significance is lacking (Arnold \& Halliday, 1988; Sherman \& Westneat, 1988; Cheng \& Siegel,
1990). However, it is as yet unclear if polyandry has a true adaptive significance, in part because experimental testing of most hypotheses related to both benefits and costs is difficult.

Our results indicate that polyandry is a heritable trait; thus the trait would be subject to genetic change under the influence of natural (or sexual) selection and consequently the level of polyandry in a given population should not be considered as species-specific, even under relatively stable environmental conditions. Moreover, environment-genotype interactions are likely to occur. The experimental demonstration of genetically mediated differences in polyandry levels among populations of the same species arising from different ecological contexts may be of great interest in the elucidation of the adaptive significance of polyandric behaviour.

We also hypothesize that genes regulating polyandry can be expected to occur in most Lepidoptera species (except for cases of strict monandry) irrespective of specific female mating frequency level in a given ecological context. Further studies in an array of species with different life histories are required to clarify if the proposed pattern is general and if autosomal polygenic control is widespread.

This is an important point, as it has been suggested that the mode of inheritance of a behavioural trait may be related with its adaptive value. For example, heritability of traits closely associated with reproductive success is often low (Falconer, 1989) reflecting reduced additive genetic variance due to stabilizing selection and, as showed here, this is not the case for polyandry since 
its broad sense heritability estimate was quite high $\left(H^{2}=0.73\right)$. Additionally, Charlesworth et al. (1987) noted that, in general, traits intimately associated with fitness tend to be X-linked and, when certain conditions are fulfilled, can have a decreased rate of fixation in response to directional selection in comparison with autosomally inherited traits (i.e. polyandry). Han \& Gatehouse (1991) suggested that the pre-reproductive period (another reproductive trait determining the number of nights over which individuals of migrant species can express their migratory potential) is an example of this. The trait, considered as highly adaptive in migratory species, has also a polygenic basis in Lepidoptera and its inheritance tends to be X-linked, at least partially, in all the noctuid species studied (Han \& Gatehouse, 1991; Hill \& Gatehouse, 1992; Wilson \& Gatehouse, 1992; Colvin \& Gatehouse, 1993). More research is needed in order to determine whether this situation may also be applied to polyandry. Additional required knowledge includes if selection acts on one or both sexes, and if there is dosage compensation on initial allele frequencies and on the coefficient of dominance (Charlesworth et al., 1987).

These two pieces of genetic evidence (an absence of $\mathrm{X}$-linkage and a high heritability) seem to suggest that polyandry in Lepidoptera could have a lower than expected impact on reproductive success and fitness. We therefore encourage genetic empirical studies, to try to find evidence for an adaptive significance for this trait, as is postulated in most hypothetical theories about this topic. As above emphasized, the experimental demonstration of the genetic control of polyandry and its mode of inheritance in an array of species is indispensable in order to support evolutionary theories and clarify the adaptive significance of this widespread trait in Lepidoptera, one of the most crucial elements of insect mating systems.

\section{Acknowledgements}

We thank Dr J. Cuartero, Dr J.N. McNeil, Dr J.F.Y. Brookfield and an anonymous referee for helpful suggestions and constructive criticism, and E. Palo, A. Blanco and J. Pérez for their technical assistance. The authors are also grateful to the SIA (Junta de Extremadura, Spain) for the financial support of this study.

\section{References}

ARNOLD, S. J. AND HALLIDAY, T. 1988. Multiple mating: natural selection is not evolution. Anim. Behav., 36, 1547-1548.

BIRKHEAD, T. R. AND MOLlER, A. P. (eds). 1998. Sperm Competition and Sexual Selection. Academic Press, San Diego.
BURNS, J. M. 1968. Mating frequency in natural populations of skippers and butterflies as determined by spermatophore counts. Proc. Nat. Acad. Sci. U.S.A., 61, 852-859.

CHARlesworth, B., COYNE, J. A. AND BARTON, N. H. 1987. The relative rates of evolution of sex chromosomes and autosomes. Am. Nat., 130, 113-146.

CHENG, K. M. AND SIEGEL, P. B. 1990. Quantitative genetics of multiple mating. Anim. Behav., 40, 406-407.

CHOE, J. C. AND CRESPI, B. J. (eds). 1997. The Evolution of Mating Systems in Insects and Arachnids. Cambridge University Press, Cambridge.

COlvin, J. AND GATEHouse, A. G. 1993. Migration and genetic regulation of the pre-reproductive period in the Cottonbollworm moth, Helicoverpa armigera. Heredity, 70, $407-412$.

CURTSINGER, J. w. 1991. Sperm competition and the evolution of multiple mating. Am. Nat., 138, 93-102.

DRUMMOND, B. A. 1984. Multiple mating and sperm competition in the Lepidoptera. In: Smith, R. L. (ed.) Sperm Competition and the Evolution of Animal Mating Systems. Academic Press, New York.

FALCONER, D. S. 1989. Introduction to Quantitative Genetics, 3rd edn. John Wiley and Sons, New York.

HAIG, D. AND BERGSTROM, C. T. 1995. Multiple mating, sperm competition and meiotic drive. J. Evol. Biol., 8, 265-282.

HALLIDAY, T. AND ARNOLD, S. J. 1987. Multiple mating by females: a perspective from quantitative genetics. Anim. Behav., 35, 939-941.

HAN, E. AND GATEHOUSE, A. G. 1991. Genetics of precalling period in the Oriental Armyworm, Mythimna separata (Walker) (Lepidoptera: Noctuidae), and implications for migration. Evolution, 45, 1502-1510.

HILL, J. K. AND GATEhOUSE, A. G. 1992. Genetic control of the pre-reproductive period in Autographa gamma (L.) (Silver Y moth) (Lepidoptera: Noctuidae). Heredity, 69, 458-464.

HUNTER, F. M., PETRIE, M., OTRONEN, M., BIRKHEAD, T. AND MOLLER, A. P. 1993. Why do females copulate repeatedly with one male? Trends Ecol. Evol., 8, 21-26.

MATHER, K. AND JINKS, J. L. 1982. Biometrical Genetics. Chapman \& Hall, London.

MCNEIL, J. N., DELISLE, J. AND CUSSON, M. 1997. Regulation of pheromone production in Lepidoptera: the need for an ecological perspective. In: Cardé, R. T. and Minks, A. K. (eds) Insect Pheromone Research, New Directions, Chapman \& Hall, New York.

PLISKE, T. E. 1973. Factors determining mating frequencies in some new world butterflies and skippers. Ann. Entomol. Soc. Am., 66, 164-169.

POITOUT, S. AND BUES, R. 1970. Élevage de plusieurs espèces de lépidoptères Noctuidae sur milieu artificiel riche et sur milieu artificiel simplifié. Ann. Zool. Ecol. Anim., 2, 79-91.

RIDLEY, M. 1988. Mating frequency and fecundity in insects. Biol. Rev., 63, 509-549.

SÁNCHEZ-MONGE, E. AND JOUvÉ, N. 1984. Genética. Omega, Barcelona.

SCHERrer, B. 1984. Biostatistique. Gaëtan Morin, Québec.

SHERMAN, P. W. AND WeSTNEAT, D. F. 1988. Multiple mating and quantitative genetics. Anim. Behav., 36, 1545-1547. 
SOKAL, R. R. AND ROHLF, F. J. 1995. Biometry. Freeman, New York.

SOLYMAR, B. D. AND CADE, w. H. 1990. Heritable variation for female mating frequency in field crickets, Gryllus integer. Behav. Ecol. Sociobiol., 26, 73-76.

THORNHILL, R. AND ALCOCK, J. 1983. The Evolution of Insect Mating Systems. Harvard University Press, Cambridge.

TORRES-VILA, L. M., STOCKEL, J. AND RODRÍGUEZ-MOLINA, M. C. 1997. Physiological factors regulating polyandry in Lobesia botrana (Lepidoptera: Tortricidae). Physiol. Entomol., 22, 387-393.

WALKER, W. F. 1980. Sperm utilization strategies in nonsocial insects. Am. Nat., 115, 780-799.
WILSON, K. AND GATEHOUSE, A. G. 1992. Migration and genetics of pre-reproductive period in the African armyworm moth, Spodoptera exempta. Heredity, 69, 255-262.

YASUI, Y. 1997. A 'good-sperm' model can explain the evolution of costly multiple mating by females. Am. Nat., 149, 573-584.

YASUI, Y. 1998. The 'genetic benefits' of female multiple mating reconsidered. Trends Ecol. Evol., 13, 246-250.

ZONNEVELD, C. 1992. Polyandry and protandry in butterflies. Bull. Math. Biol., 54, 957-976.

zONNEVELD, C. 1996. Being big or emerging early? Polyandry and the trade-off between size and emergence in male butterflies. Am. Nat., 149, 946-965. 